\title{
Dry Sliding Wear Behaviour of Titanium (Grade 5) Alloy by Using Response Surface Methodology
}

\author{
S. R. Chauhan and Kali Dass \\ Department of Mechanical Engineering, National Institute of Technology, Hamirpur 177005, India \\ Correspondence should be addressed to Kali Dass; thakurkalidass999@gmail.com
}

Received 13 February 2013; Revised 27 April 2013; Accepted 12 May 2013

Academic Editor: Huseyin Çimenoğlu

Copyright ( 2013 S. R. Chauhan and K. Dass. This is an open access article distributed under the Creative Commons Attribution License, which permits unrestricted use, distribution, and reproduction in any medium, provided the original work is properly cited.

The dry sliding wear behaviour of titanium (Grade 5) alloy has been investigated in order to highlight the mechanisms responsible for the poor wear resistance under different applied normal load, sliding speed, and sliding distance conditions. Design of experimental technique, that is, response surface methodology (RSM), has been used to accomplish the objective of the experimental study. The experimental plan for three factors at three levels using face-centre central composite design (CCD) has been employed. The results indicated that the specific wear rate increases with an increase in the applied normal load and sliding speed. However, it decreases with an increase in the sliding distance and a decrease in the sliding speed. The worn surfaces of the titanium alloy specimens were analyzed with the help of scanning electron microscope (SEM), energy dispersive spectroscopy (EDS), and X-ray diffraction (XRD) techniques. The predicted result also shows the close agreement with the experimental results and hence the developed models could be used for prediction of wear behaviour satisfactorily.

\section{Introduction}

Titanium and its alloys exhibit a unique combination of mechanical, physical, and corrosion resistance properties which have made them desirable for critical application in aerospace industries and chemical and energy industries. In comparison to light weight alloys based on aluminum, magnesium and titanium alloys present interesting possibilities as tribomaterials, but they have not been widely investigated as bearing materials [1]. The tribological concerns for titanium alloy in aerospace components have focused mainly on their fretting behavior, leading to research on surface treatments like ion implantation and solid film lubrication $[2,3]$.

However, titanium and titanium alloys generally exhibit poor fretting, wear resistance, and tribological properties even when sliding against softer materials. One of the main reasons behind poor tribological properties of titanium alloys is the low thermal conductivity of these alloys [4]. This is due to the disruption of extremely thin, low shear strength, oxide film, consisting mainly of titanium dioxide $\left(\mathrm{TiO}_{2}\right)$ which results in both depassivation and subsequent accelerated wear of the metallic surface due to the displaced particles of oxide giving rise to three-body abrasive wear [5-10].

The use of titanium alloys in sliding applications is limited because of their poor wear resistance [11]. This is due to low resistance of titanium alloys to plastic shearing as well as low protection by surface oxide formed as a consequence of high flash temperatures (induced by frictional heating) during dry sliding [12]. The poor tribological behaviour of titanium alloy is characterized by high coefficients of friction, severe adhesive wear with a strong tendency to seizing, and low abrasion resistance [13]. For this reason, different approaches by different researchers have been proposed for improving tribological properties of titanium alloys. These include surface treatment, ion implanted, coating, and oxygen diffusion [14-17].

During sliding, the heat generated is dissipated slowly and raises the interface temperature, which in turn deteriorates the tribological performance of sliding titanium. Thus the temperature of sliding surface needs to be controlled [4]. Several investigations have been conducted on dry sliding wear mechanisms of titanium alloys. Molinari et al. [18] highlighted the mechanisms responsible for the wear resistance 
TABLE 1: Chemical composition of titanium (Grade-5) alloy.

\begin{tabular}{lcccc}
\hline $\begin{array}{l}\text { Aluminum Vanadium } \\
(\mathrm{Al})\end{array}$ & $\begin{array}{c}\text { Iron } \\
(\mathrm{V})\end{array}$ & $\begin{array}{c}\text { Oxygen } \\
(\mathrm{O})\end{array}$ & $\begin{array}{c}\text { Titanium } \\
(\mathrm{Ti})\end{array}$ \\
\hline $6 \%$ & $4 \%$ & $0.25 \%$ (max.) & $0.2 \%$ (max.) & Balance \\
\hline
\end{tabular}

under different load and sliding speed conditions in selfmated Ti-6Al-4V disk-on-disk sliding tests. They found that by increasing the sliding speed, a transition from oxidative wear to delamination occurs with a corresponding minimum in the wear rate.

Basu et al. [19] found that friction and wear of high purity titanium decreased when sliding against steel in liquid nitrogen. In general, wear volume of titanium alloy for both dry and cryogenic conditions increases with increase in sliding speed, applied load, or sliding distance and this increase is more pronounced at higher levels of the variables. It is well known that interface temperature increases with increase in speed, load, and sliding distance. Also Pinto et al. [20] reported that at extreme low temperature $(4-20 \mathrm{~K})$ austenite in stainless steel and steel were transformed into martensite and this caused the stainless steel and steel to become harder, which resulted in higher wear resistance. Also it is well known that sliding of metals produces very large plastic shear strains at the sliding interface and large strain gradients in the near surface material. At high strain rates, metals and alloys frequently show narrow zones of highly localized deformation, referred to as adiabatic shear bands [21, 22].

From the above literature review, it was found that no information was available about specific wear rate of titanium (Grade 5) alloy sliding against hardened steel disc. That means that none of the published work is directly comparable to the current work. Therefore, it is intended to establish baseline data of the titanium alloy for the tribological applications. In this reported, work the three parameters such as applied normal load, sliding speed, and sliding distance are considered as independent variables. Based on the preliminary experiments, the effects of these parameters on sliding wear were tested through the set of planned experiments based on the three factors at three levels. Response surface methodology (RSM) with face-centred central composite design (CCD) has been used to develop the quadratic models for tribological behavior of the titanium (Grade 5) alloys at ambient temperature conditions.

\section{Experimental Work}

2.1. Material Used and Experimental Setup. In this work, titanium (Grade 5) alloy was tested at ambient conditions under dry sliding conditions. The titanium (Grade 5) alloy was supplied by the NISARG International (Mumbai India). The work piece material used has a dimension of $25 \mathrm{~mm}$ in length and $15 \mathrm{~mm}$ in diameter. The chemical composition of the work piece used is given in Table 1. The hardness of the titanium bar used is $35 \mathrm{HRC}$. The mechanical characteristics of titanium (Grade 5) alloy are ultimate tensile strength$950 \mathrm{MPa}$, percentage elongation $-14 \%$, and shear strength$550 \mathrm{MPa}$. This material is suitable for a wide variety of

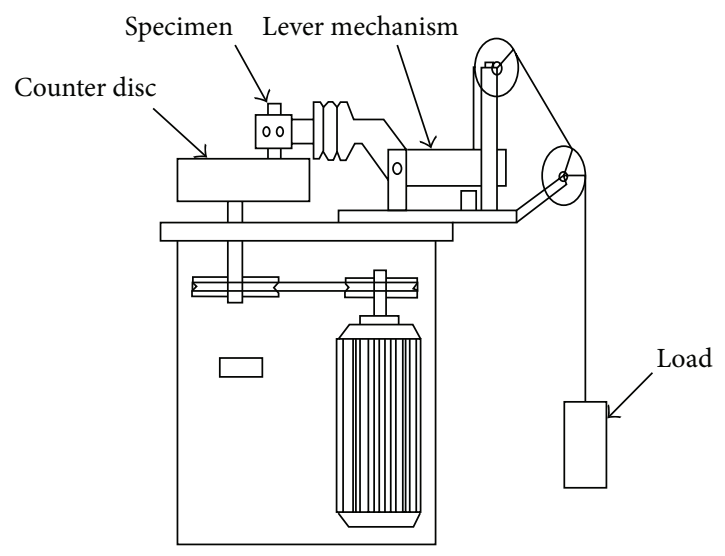

FIGURE 1: Schematic diagram of pin-on-disc apparatus.

aerospace, medical, and automotive types of applications. The dry sliding wear performance evaluation of titanium (Grade 5) alloy tests was carried out on a pin-on-disc-type friction and wear monitoring test ring (DUCOM) as per ASTM: G99 as shown in Figure 1. The counter body is a disc made of hardened ground steel (EN-32, hardness $72 \mathrm{HRC}$, surface roughness $0.7 \mu \mathrm{m} R_{a}$ ). The specimen was held stationary and the disc was rotated while a normal force was applied through a lever mechanism. During the test, friction force was measured by transducer mounted on the loading arm. The friction force readings were taken as the average of 100 readings every 40 seconds for the required period. For this purpose a microprocessor controlled data acquisition system was used. Weight loss method was used for finding the specific wear. During these experiments initial and final weight of the specimens was measured.

The material loss from the specimen surface was measured using a precision electronic balance with accuracy $\pm 0.01 \mathrm{mg}$. The specific wear rate $\left(K_{s}\right)$ can be calculated from

$$
K_{s}=\frac{\Delta M}{\rho L F_{N}}
$$

where $K_{s}$ is the specific wear rate $\left(\mathrm{mm}^{3} / \mathrm{Nm}\right), \Delta M$ is the mass loss in the test duration (g), $\rho$ is the density of the composite $\left(\mathrm{g} / \mathrm{cm}^{3}\right), L$ is the sliding distance, and $F_{N}$ is the applied normal load $(\mathrm{N})$. All the tests were conducted in ambient air conditions with temperature and humidity in the range of 26 to $30^{\circ} \mathrm{C}$ and $62 \mathrm{RH}$, respectively. The data presented in this work is in the average of at least three readings under same test conditions. Good repeatability was obtained in the wear test results.

2.2. Response Surface Methodology (RSM). Response surface methodology (RSM) is a collection of mathematical and statistical techniques that are useful for developing, improving, and optimizing processes [23]. This method has been used by some other researchers for prediction of tool life, surface roughness, wear resistance, and so forth [24]. It is commonly applied in situations where response of interest is influenced 
by several variables and the objective is to optimize this response. The Design Expert Software version 8.0.4.1 was used to develop the experimental plan for RSM. A quadratic model of second-order type was proposed to represent the relationship between specific wear rate and independent variables. The performance of the model depends on a large number of variables that can act and interact in a complex manner. In the present work, the applied normal load, speed, and sliding distance are considered as independent variables and the response (output) variable is the specific wear rate $(y)$. In RSM, the quantitative form of the relationship between the desired response and the independent input variables can be represented as shown in the following equations:

$$
y=f(A, B, C)
$$

where $y$ is the desired response and $f$ is the response function (or response surface). A quadratic model can be expressed as

$$
\begin{aligned}
y= & a_{0}+\sum_{i=1}^{k} a X_{i}+\sum_{i=1}^{k} a_{i j} X_{j}^{2} \\
& +\sum_{i<j}^{k} \sum_{j}^{k} a_{i j} X_{i} X_{j}+e \quad \text { for } i<j,
\end{aligned}
$$

where $a_{0}$ is constant and $i, j$ are the linear and quadratic coefficients, respectively. While " $a$ " is regression coefficient, $k$ is the number of factors investigated and optimized in the experiments. And " $e$ " is random error. When developing the quadratic equation, the test factors were coded according to the following equation:

$$
x_{i}=\frac{X_{i}-X_{0}}{\Delta X_{i}}, \quad \text { where } i=1,2,3, \ldots, k
$$

where $x_{i}, X_{i}$, and $X_{0}$ are the dimensionless value, real value, and real value (centre point) of the independent variable and $\Delta X_{i}$ is the step change value. Using this quadratic model of $y$ in this study is not only to investigate over the entire factor space but also to locate the region where the desired target is located where the response approaches its optimum or near optimal value. The necessary data for the quadratic models have been collected by the machining experiments based on response surface methodology (RSM) by using face-centered central composite design. The central composite design is a first-order $\left(2^{n}\right)$ design augmented by additional centre and axial points to allow estimation of the tuning parameters of a second order model. The factorial portion of the CCD is the full factorial design with all combinations of the factors at two levels (low -1 and high +1 ) and composed of the eight star points and six central points which are the midpoints between the high and low levels. The star points at the face of the cubic portion on the design which corresponds to $\alpha$ value of 1 and this type of design are commonly called the face centered. The three machining parameters at three levels with their ranges are presented in Table 2.

\section{Results and Discussion}

The actual values (design matrix) and response (specific wear rate) from the machining runs performed as per the experimental plan are shown in Table 3. The experimental plans were developed for establishing the quadratic model for specific wear rate. These results were input into the Design Expert software for further analysis. The analysis of variance (ANOVA) was applied to summarize the various tests performed, that is, the test for significance of the regression model, the test for significance of individual model coefficients and the test for lack of fit.

3.1. ANOVA Analysis. In the ANOVA analysis, the test for significance of the regression model, test for significance on individual model coefficients, and test for lack of fit are needed to be performed. In the ANOVA tables the insignificant model terms can be removed by selecting the backward elimination procedure. Table 4 is the ANOVA table for the reduced quadratic model for specific wear rate. The value of "Prob. $>F$ " in Table 4 for model is less than 0.05 which indicates that the model is significant, and this is desirable as it indicates that the terms in the model have a significant effect on the response. The determination coefficient $R^{2}$ in Table 4 is a measure of the degree of fit. When $R^{2}$ approaches to unity, the best response model fits the actual data. It that indicates less is the difference between the predicted and actual values is less. The model $F$ value of 331.67 implies that the model is significant. There is only a $0.01 \%$ chance that a model $F$ value this large could occur due to noise. Values of "Prob. $>F$ " less than 0.0500 indicate that model terms are significant. In this case $B, C, A B, B C, A^{2}, B^{2}$, and $C^{2}$ are significant model terms. Values greater than 0.1000 indicate that the model terms are not significant. If there are many insignificant model terms (not counting those required to support hierarchy), model reduction may improve the model. The lack-of-fit $F$ value of 3.91 implies that there is a $8.05 \%$ chance that a Lack-of-fit $F$ value this large could occur due to noise. The "predicted $R$-squared of 0.9653 is in reasonable agreement with the Adjusted $R$-squared of 0.9937. "Adeq Precision" measures the signal-to-noise ratio. A ratio greater than 4 is desirable. In this work, the Adeq Precision ratio of 55.817 indicates an adequate signal. This model can be used to navigate the design space.

The following equations are the final quadratic model for specific wear rate in terms of coded and actual factors and are shown as follows:

Specific wear rate $(\mathrm{mm} 3 / \mathrm{Nm})$ in terms of coded factors

$$
\begin{aligned}
= & +2.82-0.015 \times A+0.34 \times B-0.068 \times C \\
& -0.029 \times A \times B-0.014 \times A \times C+0.024 \times B \times C \\
& +0.056 \times A^{2}-0.15 \times B^{2}-0.20 \times C^{2},
\end{aligned}
$$


TABLE 2: Design layout of independent variables and their levels.

\begin{tabular}{lcccc}
\hline Variables & Units & Low level $(-1)$ & Medium level $(0)$ & High level $(+1)$ \\
\hline Sliding speed $(A)$ & Rev/min & 200 & 400 & 600 \\
Applied normal load $(B)$ & $\mathrm{N}$ & 50 & 70 & 90 \\
Sliding distance $(C)$ & $\mathrm{m}$ & 1000 & 1500 & 2000 \\
\hline
\end{tabular}

TABLE 3: Design layout matrix and experimental results.

\begin{tabular}{|c|c|c|c|c|}
\hline Run & Sliding speed (rev/min) & Applied normal load (N) & Sliding distance $(\mathrm{m})$ & $\begin{array}{c}\text { Response } \\
\text { Specific wear rate } \times 10^{-1}\left(\mathrm{~mm}^{3} / \mathrm{Nm}\right)\end{array}$ \\
\hline 1 & 400 & 50 & 1500 & 2.34 \\
\hline 2 & 200 & 50 & 2000 & 2.12 \\
\hline 3 & 400 & 70 & 1500 & 2.84 \\
\hline 4 & 400 & 70 & 1500 & 2.85 \\
\hline 5 & 400 & 90 & 1500 & 2.99 \\
\hline 6 & 600 & 50 & 1000 & 2.32 \\
\hline 7 & 400 & 70 & 2000 & 2.55 \\
\hline 8 & 600 & 70 & 1500 & 2.88 \\
\hline 9 & 600 & 90 & 1000 & 2.87 \\
\hline 10 & 200 & 90 & 2000 & 2.88 \\
\hline 11 & 400 & 70 & 1500 & 2.81 \\
\hline 12 & 200 & 70 & 1500 & 2.86 \\
\hline 13 & 200 & 90 & 1000 & 2.97 \\
\hline 14 & 400 & 70 & 1500 & 2.82 \\
\hline 15 & 400 & 70 & 1500 & 2.82 \\
\hline 16 & 400 & 70 & 1500 & 2.83 \\
\hline 17 & 600 & 50 & 2000 & 2.08 \\
\hline 18 & 400 & 70 & 1000 & 2.68 \\
\hline 19 & 600 & 90 & 2000 & 2.78 \\
\hline 20 & 200 & 50 & 1000 & 2.25 \\
\hline
\end{tabular}

TABLE 4: The results of ANOVA table for quadratic model for specific wear rate $\times 10^{-1}\left(\mathrm{~mm}^{3} / \mathrm{Nm}\right)$.

\begin{tabular}{|c|c|c|c|c|c|c|}
\hline Source & Sum of squares & $\mathrm{df}$ & Mean square & $F$ value & Prob. $>F$ & \\
\hline Model & 1.59 & 9 & 0.18 & 331.67 & $<0.0001$ & Significant \\
\hline$A$-speed & $2.250 E-003$ & 1 & $2.250 E-003$ & 4.23 & 0.0667 & \\
\hline$B$-load & 1.14 & 1 & 1.14 & 2149.00 & $<0.0001$ & \\
\hline$C$-sliding distance & 0.046 & 1 & 0.046 & 86.98 & $<0.0001$ & \\
\hline$A B$ & $6.612 E-003$ & 1 & $6.612 E-003$ & 12.44 & 0.0055 & \\
\hline$A C$ & $1.512 E-003$ & 1 & $1.512 E-003$ & 2.85 & 0.1225 & \\
\hline$B C$ & $4.513 E-003$ & 1 & $4.513 E-003$ & 8.49 & 0.0155 & \\
\hline$A^{2}$ & $8.736 E-003$ & 1 & $8.736 E-003$ & 16.43 & 0.0023 & \\
\hline$B^{2}$ & 0.061 & 1 & 0.061 & 114.28 & $<0.0001$ & \\
\hline$C^{2}$ & 0.11 & 1 & 0.11 & 204.11 & $<0.0001$ & \\
\hline Residual & $5.316 E-003$ & 10 & $5.316 E-003$ & & & \\
\hline Lack of fit & $4.233 E-003$ & 5 & $8.466 E-004$ & 3.91 & 0.0805 & Not significant \\
\hline Pure error & $1.082 E-003$ & 5 & $2.167 E-004$ & & & \\
\hline Cor total & 1.59 & 19 & & & & \\
\hline S.D. & 0.023 & & quared & & & \\
\hline Mean & 2.68 & & $R$-squared & & & \\
\hline C.V\% & 0.86 & & $\mathrm{~d} R$-squared & & & \\
\hline PRESS & 0.055 & & Precision & & & \\
\hline
\end{tabular}




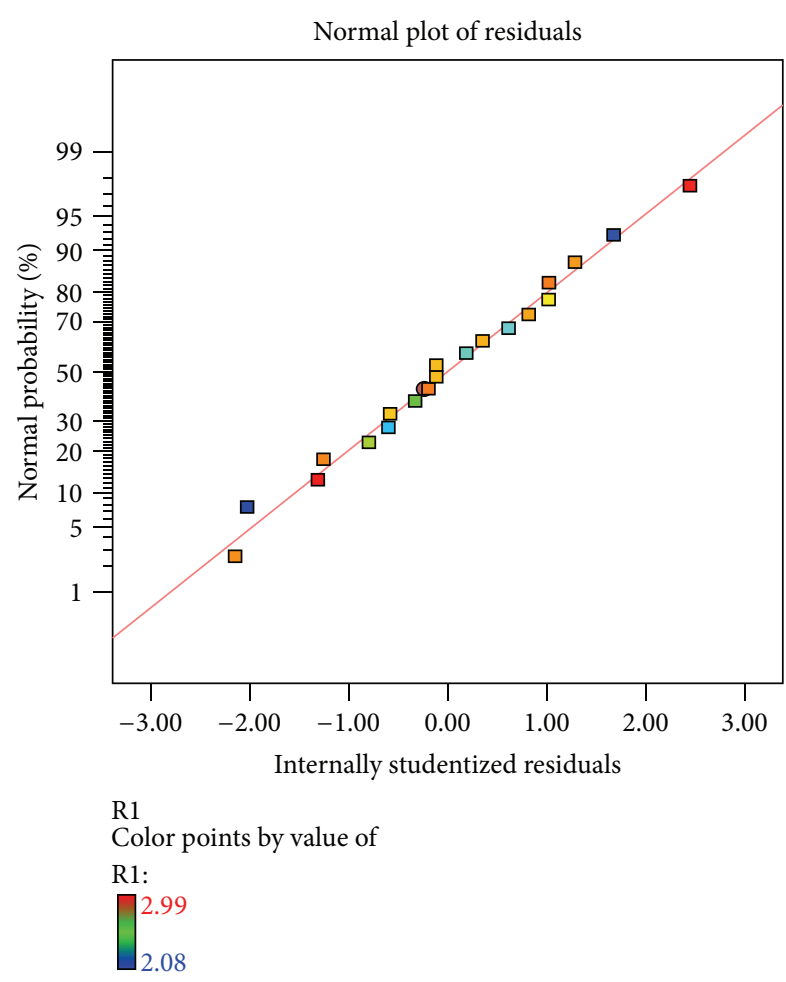

FIGURE 2: Normal probability plot of residuals for specific wear rate $\left(\mathrm{mm}^{3} / \mathrm{Nm}\right)$.

Specific wear rate $(\mathrm{mm} 3 / \mathrm{Nm})$ in terms of actual factors

$$
\begin{aligned}
& =-1.54399-4.92898 E-004 \times \text { Speed } \\
& +0.06823 \times \text { Applied normal load } \\
& +2.13639 E-003 \times \text { Sliding distance } \\
& -7.18750 E-006 \times \text { Speed } \times \text { Applied normal load } \\
& -1.37500 E-007 \times \text { Speed } \times \text { Sliding distance } \\
& +2.37500 E-006 \times \text { Applied normal load } \\
& \times \text { Sliding distance }+1.40909 E-006 \times \text { Speed }^{2} \\
& -3.71591 E-004 \times \text { Applied normal load } \\
& -7.94545 E-007 \times \text { Sliding distance } \\
&
\end{aligned}
$$

3.2. Effect of Independent Parameters on Specific Wear Rate. From the results of the ANOVA Table 4, a model adequacy checking was performed in order to verify that the quadratic model for specific wear rate of the regression analysis is not violated. The normal probability plot of the residual for specific wear rate is shown in Figure 2 which shows no sign of violation of the independence or constant assumption. Since each point in the plot follows a straight line pattern implying that the errors are distributed normally. The above model obtained can be used to predict the specific wear rate within

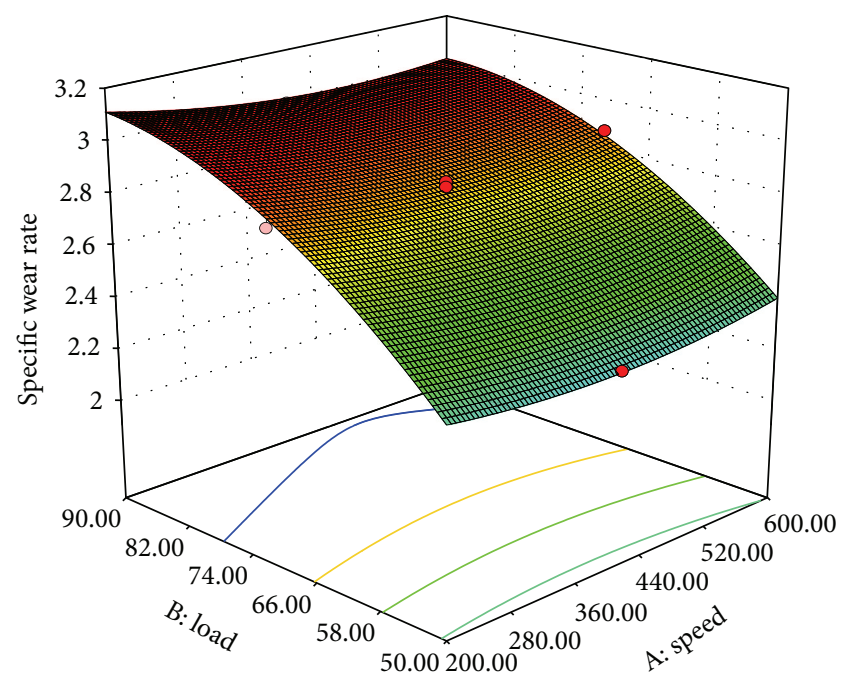

Factor coding: actual

Specific wear rate

- Design points above predicted value

- Design points below predicted value

2.99

2.08

$X_{1}=$ A: speed

$X_{2}=$ B: load

Actual factor

C: sliding distance $=1500.00$

FIGURE 3: 3D response plot for specific wear rate $\left(\mathrm{mm}^{3} / \mathrm{Nm}\right)$ with the change of applied normal load and sliding speed.

the limits of the factors investigated. However, in general recognition the wear characteristics are strongly dependent on load, sliding speed, sliding time (distance), temperature, contact geometry, surface roughness, ambient atmosphere, and material surface compositions.

In order to investigate the effects of independent parameters on specific wear rate, the three-dimensional (3D) response surfaces plot is drawn and shown in Figures 3, 4, and 5 , respectively. Figures 3 and 4 show the $3 \mathrm{D}$ response surface for specific wear rate with the change of applied normal load $\times$ speed and sliding distance $\times$ speed, respectively. Also Figure 5 shows the $3 \mathrm{D}$ response surface for specific wear rate with the change of applied normal load $\times$ sliding distance, respectively. The results from Figures 3 and 4 show that the specific wear rate increases with an increase in the applied normal load and sliding speed and decreases with an increase in the sliding distance and decrease in the sliding speed. This phenomenon may be caused due to the formation of a thin oxide layer at high sliding distance as a result of the reaction between the steel and titanium alloy in the surrounding air and in addition the thin oxide layer can also act as a solid lubrication thus reducing the friction and specific wear rate. Also the results from Figure 5 show that the specific wear rate increases with an increase in the applied normal load. Whereas the specific wear rate decreases with an increase in the sliding 


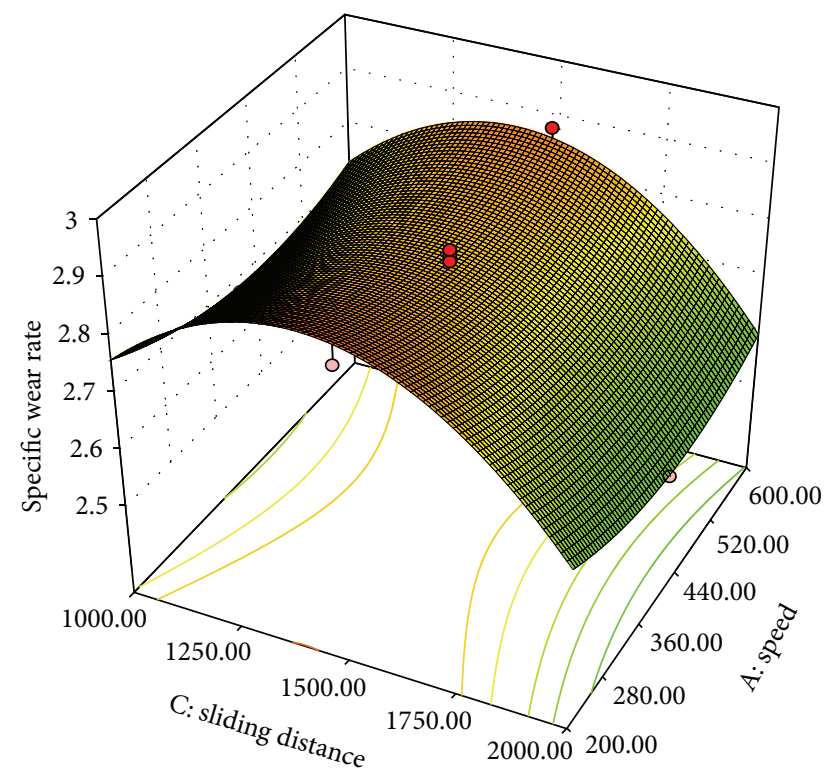

Factor coding: actual

Specific wear rate

- Design points above predicted value

- Design points below predicted value

2.99

2.08

$X_{1}=$ C: sliding distance

$X_{2}=$ A: speed

Actual factor

B: load $=70.00$

FIGURE 4: The 3D response plot for specific wear rate $\left(\mathrm{mm}^{3} / \mathrm{Nm}\right)$ with the change of sliding distance and sliding speed.

distance. This could be due to the reason that with an increase in the sliding distance the temperature rise increases to a critical value at which the titanium alloy specimen surface gets oxidized because of its low thermal conductivity. This oxidized surface of titanium alloy either gets fragmented or becomes stable to some extent. The formed fragmented oxide layer or particles sometimes acts as lubricating agent and thus this oxide layer reduces the specific wear rate. Hence the specific wear rate decreases with an increase in the sliding distance, respectively.

3.3. Analysis of Wear Debris and Worm Surfaces. The analysis of the wear debris and worm surface was performed with the help of X-ray diffraction (XRD), scanning electron microscope (SEM), and energy dispersive spectroscopy (EDS) techniques. The XRD spectra were performed by a PANalytial - X'Pert PRO (Netherlands) operated at $45 \mathrm{kV}$ and $40 \mathrm{~mA}$ current and in the range of $2(\theta)$, that is, $5^{\circ}$ to $120^{\circ}$. The SEM and EDS analysis was performed by a FEI quanta FEG450 machine. The specimens are mounted on stubs with gold plating. To enhance the conductivity of the specimens, thin film of platinum was vacuum evaporated onto them before the photomicrographs were taken.

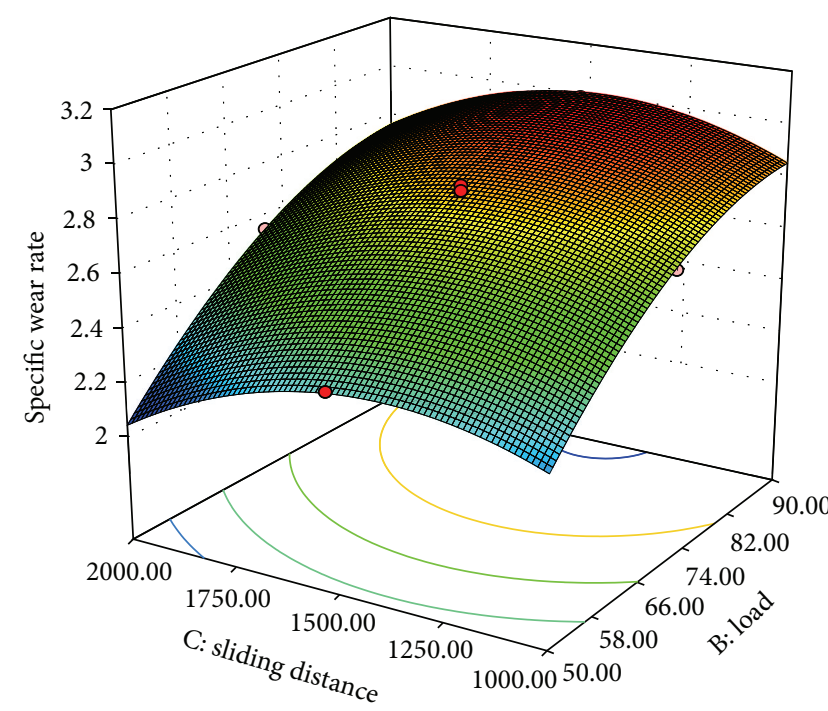

Factor coding: actual Specific wear rate

- Design points above predicted value - Design points below predicted value

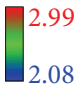

$X_{1}=$ B: load

$X_{2}=$ C: sliding distance

Actual factor

A: speed $=400.00$

FIGURE 5: 3D response plot for specific wear rate $\left(\mathrm{mm}^{3} / \mathrm{Nm}\right)$ with the change of sliding distance and applied normal load.

Figure 6 shows the XRD spectra of the wear debris produced by the tests at applied normal load of (a) $50 \mathrm{~N}$ and (b) $90 \mathrm{~N}$ at a sliding speed of $600 \mathrm{rpm}$, respectively. It was found that the debris produced at low applied normal load comprises of $\mathrm{TiO}$ and $\alpha$-Ti alloy and a little amount of Fe- $\alpha$ alloy. However, a large amount of tribooxides formed on worn surfaces under an applied normal load of $50 \mathrm{~N}$ is shown in Figure 6(a) because the peaks corresponding to oxides surpassed those of $\alpha$-Ti alloy. This implies that an oxidation wear occurs during the sliding test at low applied normal load conditions, whereas during sliding at high applied normal load conditions the amount of tribooxides decreased. At applied normal load of $90 \mathrm{~N}$, the only $\alpha$-Ti was the predominant phase and no tribooxide was identified as shown in Figure 6(b).

The morphological analysis of the wear fragments confirms the above results. Figures 7(a) and 7(b) present SEM micrograph of titanium (Grade 5) alloy after dry sliding conditions at sliding speed of $600 \mathrm{rpm}$ and applied normal load of (a) $50 \mathrm{~N}$ and (b) $90 \mathrm{~N}$, respectively. Figure 7(a) shows the smooth wear surface in comparison to Figure 7(b). Also at low applied normal load, the wear track indicates a microfragmentation process and on the other hand at high applied normal load, the brittle detachment of large particles from the surface is clearly seen. Also at low applied normal load, the titanium alloy presented typical adhesive traces and 


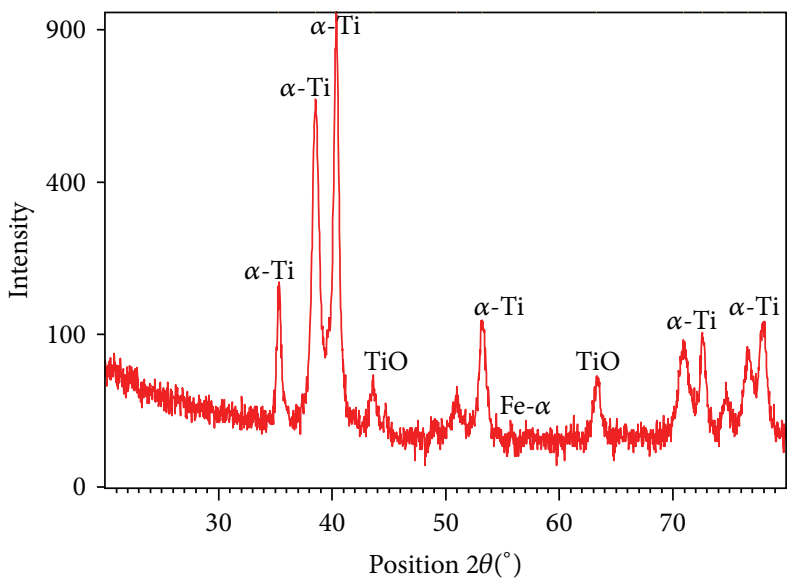

(a)

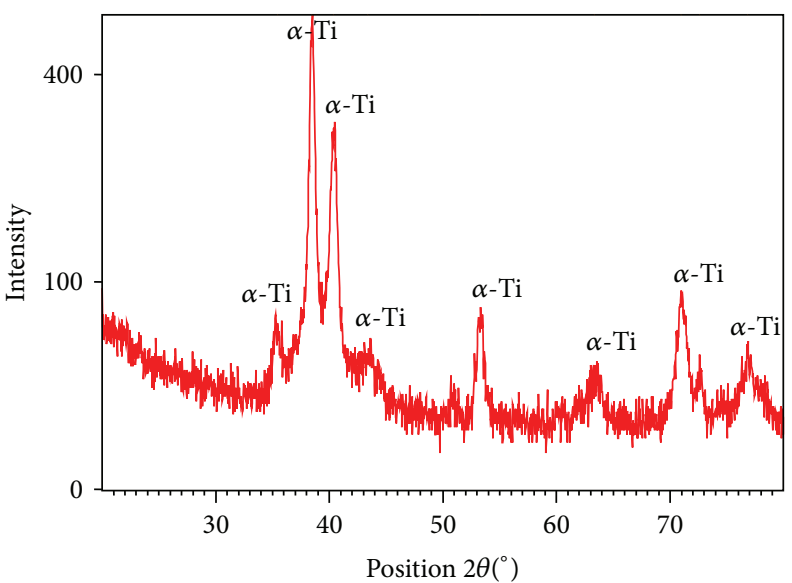

(b)

FIGURE 6: XRD spectra of debris produced at sliding speed of $600 \mathrm{rpm}$ and applied normal load of (a) $50 \mathrm{~N}$ and (b) $90 \mathrm{~N}$.

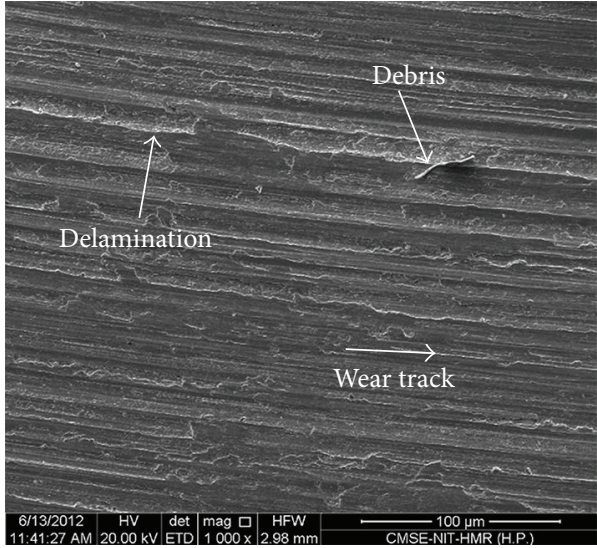

(a)

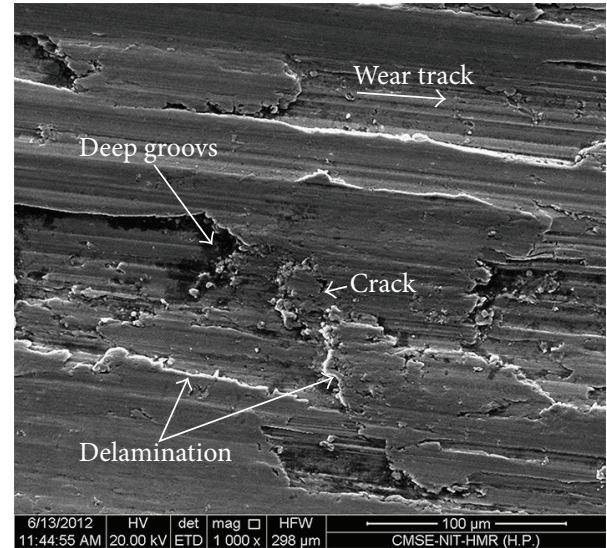

(b)

FIGURE 7: SEM of titanium (Grade 5) alloy after dry sliding conditions at sliding speed of $600 \mathrm{rpm}$ and applied normal load of (a) $50 \mathrm{~N}$ and (b) $90 \mathrm{~N}$, respectively.

abrasive furrows, whereas with an increase in applied normal load the worn surfaces became relatively rougher, with many ripped regions and abrasive furrows. Also Figure 7 (a) showed some debris and delamination occurring during sliding at low applied normal load conditions, whereas from Figure 7(b) shows some deep grooves, cracks and delamination was occurred during sliding at high applied normal load conditions, respectively. The general wear pattern seems to be ploughing out of the material from the worm surface. The grooves on the worm surface were coarse and the plastic deformation at the edges of grooves was heavy thus resulting in wear rate. Also from the above investigations, it was found that the wear behaviour of titanium alloy sliding against hardened steel is a function of cyclic count, sliding velocity, contact stress, and alloy structure.

Figures 8(a) and 8(b) present the EDS spectrum of titanium (Grade 5) alloy under dry sliding conditions at sliding speed of $600 \mathrm{rpm}$ and applied normal load of $50 \mathrm{~N}$ and $90 \mathrm{~N}$, respectively. According to the EDS analysis as shown in Figure 8(a), the presence of metals that have been detected is Ti, O, Al, Fe, and C. Similarly, Figure 8(b) shows the presences of metals that have been detected as $\mathrm{Ti}, \mathrm{C}, \mathrm{Al}$, and $\mathrm{Fe}$, respectively. When sliding at applied normal load of $50 \mathrm{~N}$ and sliding speed of $600 \mathrm{rpm}$, a high content of oxygen and carbon appeared on the worn surface, but only traces of oxide were formed in this situation. Thus they could not be identified by EDS analysis. It was found that when sliding at applied load of $90 \mathrm{~N}$ and sliding speed of $600 \mathrm{rpm}$ the oxygen content on the worn surfaces disappeared and almost no tribooxides were identified. Because of absence of tribooxide layer the wear under an applied normal of $90 \mathrm{~N}$ was observed both adhesive and abrasive wear [25]. Thus it is clear that the formation of tribooxides depended on a certain ambient temperature and applied normal load conditions. 

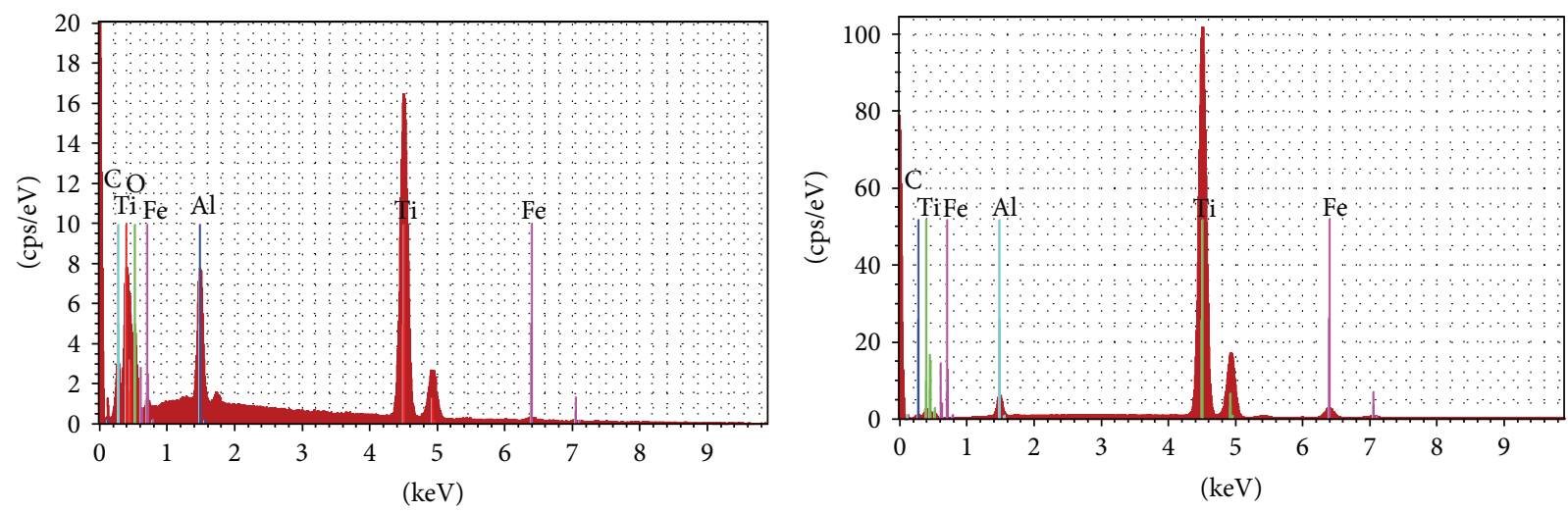

\begin{tabular}{lccc}
$\mathrm{E} 1$ & $\begin{array}{c}\text { Norm.c } \\
\text { (wt.\%) }\end{array}$ & $\begin{array}{c}\text { Atom.c } \\
\text { (at. wt.\%) }\end{array}$ & $\begin{array}{c}\text { Error.c } \\
\text { (wt. 5) }\end{array}$ \\
\hdashline $\mathrm{Ti}$ & 76.43 & 55.98 & 2.7 \\
$\mathrm{O}$ & 11.31 & 24.80 & 1.6 \\
$\mathrm{Al}$ & 4.47 & 5.82 & 0.2 \\
$\mathrm{Fe}$ & 4.07 & 10.85 & 0.3 \\
$\mathrm{C}$ & 3.72 & 10.85 & 0.6 \\
\hdashline Total & 100.00 & 100.00 &
\end{tabular}

(a)

\begin{tabular}{lccc}
$\mathrm{E} 1$ & $\begin{array}{c}\text { Norm.c } \\
\text { (wt.\%) }\end{array}$ & $\begin{array}{c}\text { Atom.c } \\
\text { (at. wt.\%) }\end{array}$ & $\begin{array}{c}\text { Error.c } \\
\text { (wt. 5) }\end{array}$ \\
\hdashline $\mathrm{Ti}$ & 85.59 & 70.64 & 2.3 \\
$\mathrm{O}$ & 6.17 & 20.29 & 0.9 \\
$\mathrm{Al}$ & 4.29 & 6.28 & 0.2 \\
$\mathrm{Fe}$ & 3.77 & 3.96 & 2.80 \\
\hdashline Total & 95.17 & 100.00 &
\end{tabular}

(b)

FIGURE 8: EDS spectrum of titanium (Grade 5) alloy under dry sliding conditions at sliding speed of $600 \mathrm{rpm}$ and applied normal load of (a) $50 \mathrm{~N}$ and (b) $90 \mathrm{~N}$, respectively.

Also the weight, atomic, and error measurement percentage contributions of the detected metal elements are shown in Figures $8(\mathrm{a})$ and $8(\mathrm{~b})$, respectively.

\section{Confirmation Test}

The three confirmation experiments are performed for the specific wear rate in order to verify the adequacy of obtained quadratic models (5) and (6). The results of the conformation runs and their comparisons with the predicted values for the specific wear rate are presented in Table 5. The results of Table 5 showed that both the residual and percentage errors are small. The percentage error between the actual and the predicted value of specific wear rate lies between the range of -0.88 and 0.71 , respectively. All the experimental values of confirmation test are within the $95 \%$ prediction interval. Therefore, it is obviously demonstrated that the obtained equations (5) and (6) are excellently accurate quadratic models for titanium (Grade 5) alloy for the selected level of input variables.

\section{Conclusions}

In this paper, the reduced quadratic model for specific wear rate has been developed to investigate the tribological behaviour of titanium (Grade 5) alloy under dry sliding conditions against a steel disc by using response surface methodology. The effects of wear variables such as sliding speed, applied normal load, and sliding distance have been
TABLE 5: The results of conformation experiment.

\begin{tabular}{lccccccc}
\hline \multirow{2}{*}{ Number } & \multicolumn{4}{c}{ Variables } & \multicolumn{3}{c}{ Specific wear rate $\times 10^{-1}\left(\mathrm{~mm}^{3} / \mathrm{Nm}\right)$} \\
& $(A)$ & $(B)$ & $(C)$ & Actual & Predicted & Residual & Error $(\%)$ \\
\hline$(1)$ & 200 & 50 & 1000 & 2.25 & 2.27 & -0.02 & -0.88 \\
$(2)$ & 400 & 70 & 1500 & 2.81 & 2.82 & 0.01 & 0.35 \\
$(3)$ & 600 & 90 & 2000 & 2.78 & 2.76 & 0.02 & 0.71 \\
\hline
\end{tabular}

evaluated. The following conclusions are drawn based on the experimental investigations.

(i) The specific wear rate increases with an increase in the normal applied load and speed and decreases with an increase in the sliding distance and a decrease in the speed.

(ii) The predicted and the measured values are satisfactorily close to each other which indicates that the developed quadratic model can be effectively used for predicting the specific wear rate of titanium alloy with $95 \%$ confidential level.

(iii) From the XRD spectrum analysis it was found that at low applied normal load condition the large amount of tribooxides was formed on worn surfaces of titanium alloy, whereas, as with increase in applied normal load, the amount of tribooxides decreases.

(iv) It was found from the SEM images that at low applied normal load the wear track indicates a microfragmentation process, and on the other hand at high applied 
normal load the brittle detachment of large particles from the surface is clearly seen.

\section{References}

[1] J. Qu, P. J. Blau, T. R. Watkins, O. B. Cavin, and N. S. Kulkarni, "Friction and wear of titanium alloys sliding against metal, polymer, and ceramic counterfaces," Wear, vol. 258, no. 9, pp. 1348-1356, 2005.

[2] R. B. Waterhouse and A. Iwabuchi, "The effect of ion implantation on the fretting wear of four titanium alloys at temperatures up to $600^{\circ} \mathrm{C}$," in Proceedings of the International Conference on Wear of Materials, pp. 471-484, ASME, New York, NY, USA, 1985.

[3] K. G. Budinski, "Tribological properties of titanium alloys," Wear, vol. 151, no. 2, pp. 203-217, 1991.

[4] N. S. M. El-Tayeb, T. C. Yap, and P. V. Brevern, "Wear characteristics of titanium alloy Ti54 for cryogenic sliding applications," Tribology International, vol. 43, no. 12, pp. 2345-2354, 2010.

[5] J. Rieu, A. Pichat, L.-M. Rabbe, A. Rambert, C. Chabrol, and M. Robelet, "Structural modifications induced by ion implantation in metals and polymers used for orthopaedic prostheses," Materials Science and Technology, vol. 8, no. 7, pp. 589-593, 1992.

[6] R. A. Buchanan, E. D. Ridney Jr., and J. M. Williams, "Wear-accelerated corrosion of Ti-6A1-4V and nitrogen-ionimplanted Ti-6A1-4V: mechanisms and influence of fixed-stress magnitude," Journal of Biomedical Materials Research, vol. 21, no. 3, pp. 367-377, 1987.

[7] F. M. Kustas and M. S. Misra, "Friction and wear of titanium alloys," in Friction, Lubrication, and Wear Technolog ASM Handbook, S. D. Henry and P. J. Blau, Eds., vol. 18, pp. 778-785, ASM International, Materials Park, Ohio, USA, 1992.

[8] F. G. A. de Laat and T. Adams, Inhibiting the Wear and Galling Characteristics of Titanium, Metals Engineering Quarterly, The American Society for Metals, 1968.

[9] J. A. Davidson, "Analysis of clinical and laboratory wear factors and the tribological performance of orthopaedic implants," Japanese Journal of Tribology, vol. 37, no. 4, pp. 399-413, 1992.

[10] P. D. Miller and J. W. Holladay, "Friction and wear properties of titanium," Wear, vol. 2, no. 2, pp. 133-140, 1958.

[11] K. G. Budinski, "Tribological properties of titanium alloys," Wear, vol. 151, no. 2, pp. 203-217, 1991.

[12] S. Yerramareddy and S. Bahadur, "Effect of operational variables, microstructure and mechanical properties on the erosion of Ti-6Al-4V," Wear, vol. 142, no. 2, pp. 253-263, 1991.

[13] L. Ceschini, E. Lanzoni, C. Martini, D. Prandstraller, and G. Sambogna, "Comparison of dry sliding friction and wear of Ti6Al4V alloy treated by plasma electrolytic oxidation and PVD coating," Wear, vol. 264, no. 1-2, pp. 86-95, 2008.

[14] H. Dong and T. Bell, "Enhanced wear resistance of titanium surfaces by a new thermal oxidation treatment," Wear, vol. 238, no. 2, pp. 131-137, 2000.

[15] H. Schmidt, A. Schminke, and D. M. Rück, "Tribological behaviour of ion-implanted Ti6A14V sliding against polymers," Wear, vol. 209, no. 1-2, pp. 49-56, 1997.

[16] C. Met, L. Vandenbulcke, and M. C. Sainte Catherine, "Friction and wear characteristics of various prosthetic materials sliding against smooth diamond-coated titanium alloy," Wear, vol. 255, no. 7-12, pp. 1022-1029, 2003.

[17] S. Krol, W. Grzesik, Z. Zalisz, and M. Hepner, "Frictional behaviour of oxygen diffusion hardened titanium in dry sliding against Co-28Cr-5W-4Fe-3Ni-1Si cobalt alloy," Tribology International, vol. 37, no. 8, pp. 633-643, 2004.

[18] A. Molinari, G. Straffelini, B. Tesi, and T. Bacci, "Dry sliding wear mechanisms of the Ti6A14V alloy," Wear, vol. 208, no. 1-2, pp. 105-112, 1997.

[19] B. Basu, J. Sarkar, and R. Mishra, "Understanding friction and wear mechanisms of high-purity titanium against steel in liquid nitrogen temperature," Metallurgical and Materials Transactions A, vol. 40, no. 2, pp. 472-480, 2009.

[20] H. Pinto, A. Pyzalla, R. Büscher, A. Fischer, K. Aßmus, and W. Hübner, "The effect of hydrogen on the deterioration of austenitic steels during wear at cryogenic temperature," Wear, vol. 259, no. 1-6, pp. 424-431, 2005.

[21] D. A. Rigney, "Comments on the sliding wear of metals," Tribology International, vol. 30, no. 5, pp. 361-367, 1997.

[22] S. Liao and J. Duffy, "Adiabatic shear bands in a TI-6A1-4V titanium alloy," Journal of the Mechanics and Physics of Solids, vol. 46, no. 11, pp. 2201-2231, 1998.

[23] Timetal datasheet for Ti6Al4V, 2009, http://www.timet .com/pdfs/6-4.pdf.

[24] Timetal datasheet for Ti-5Al-4V-0.6Mo-0.4Fe, 2009, http:// www.timet.com/pdfs/54M.pdf.

[25] X. H. Cui, Y. S. Mao, M. X. Wei, and S. Q. Wang, "Wear characteristics of Ti-6Al-4V Alloy at $20-400^{\circ} \mathrm{C}$," Tribology Transactions, vol. 55, no. 2, pp. 185-190, 2012. 

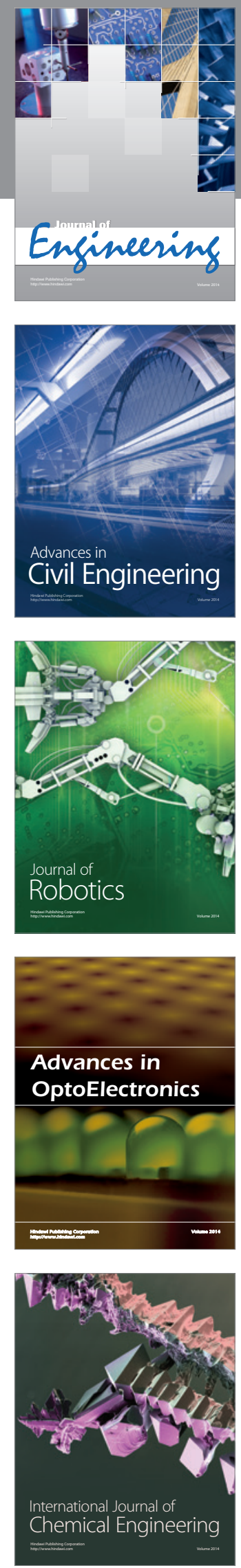

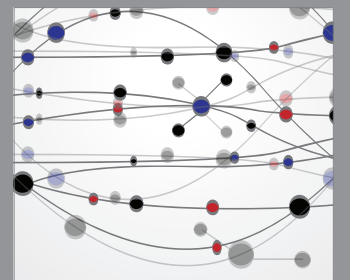

The Scientific World Journal
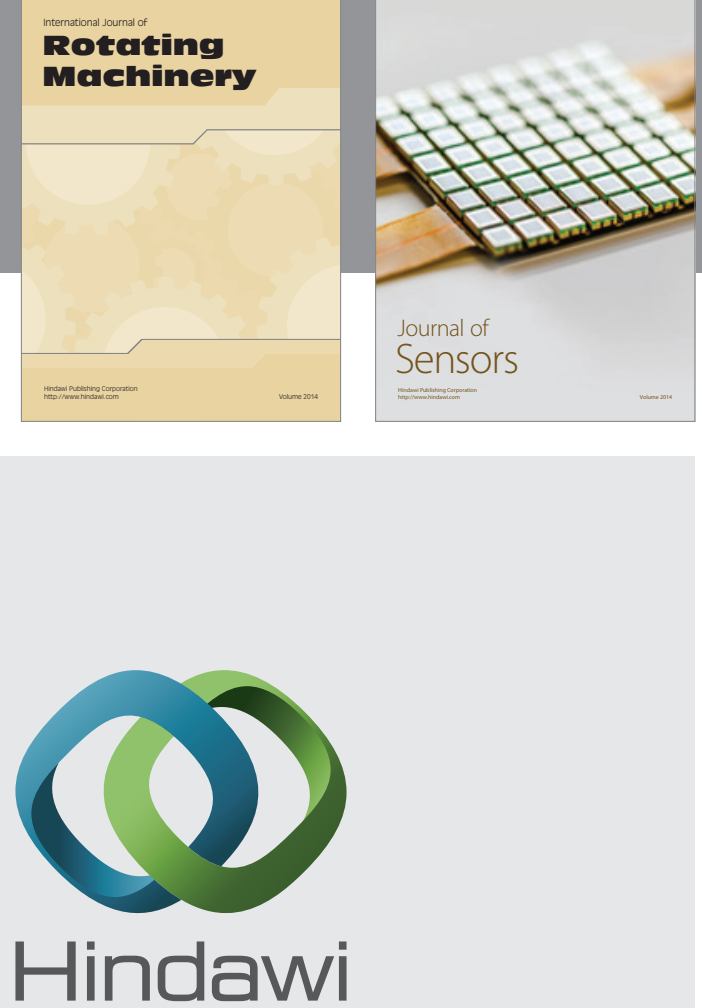

Submit your manuscripts at http://www.hindawi.com
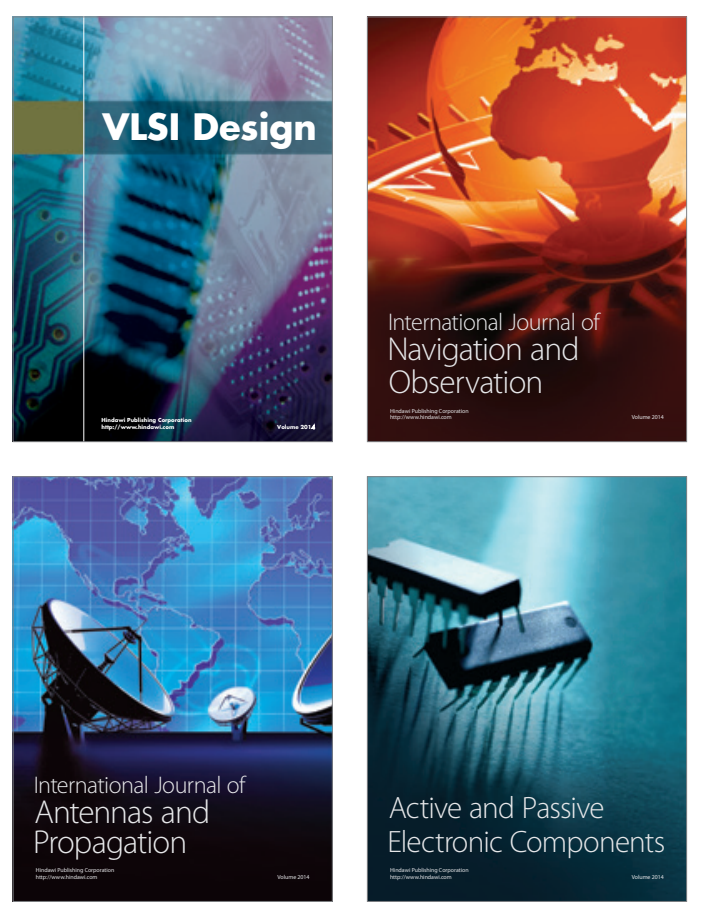
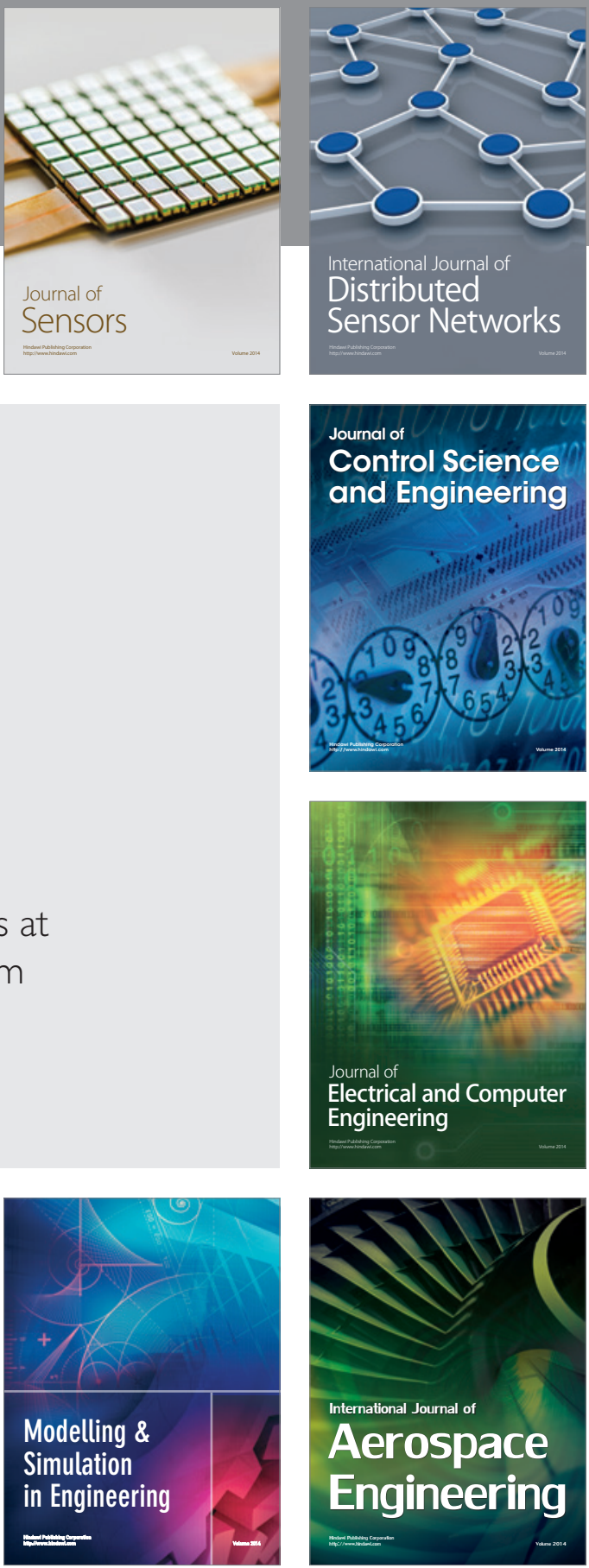

Journal of

Control Science

and Engineering
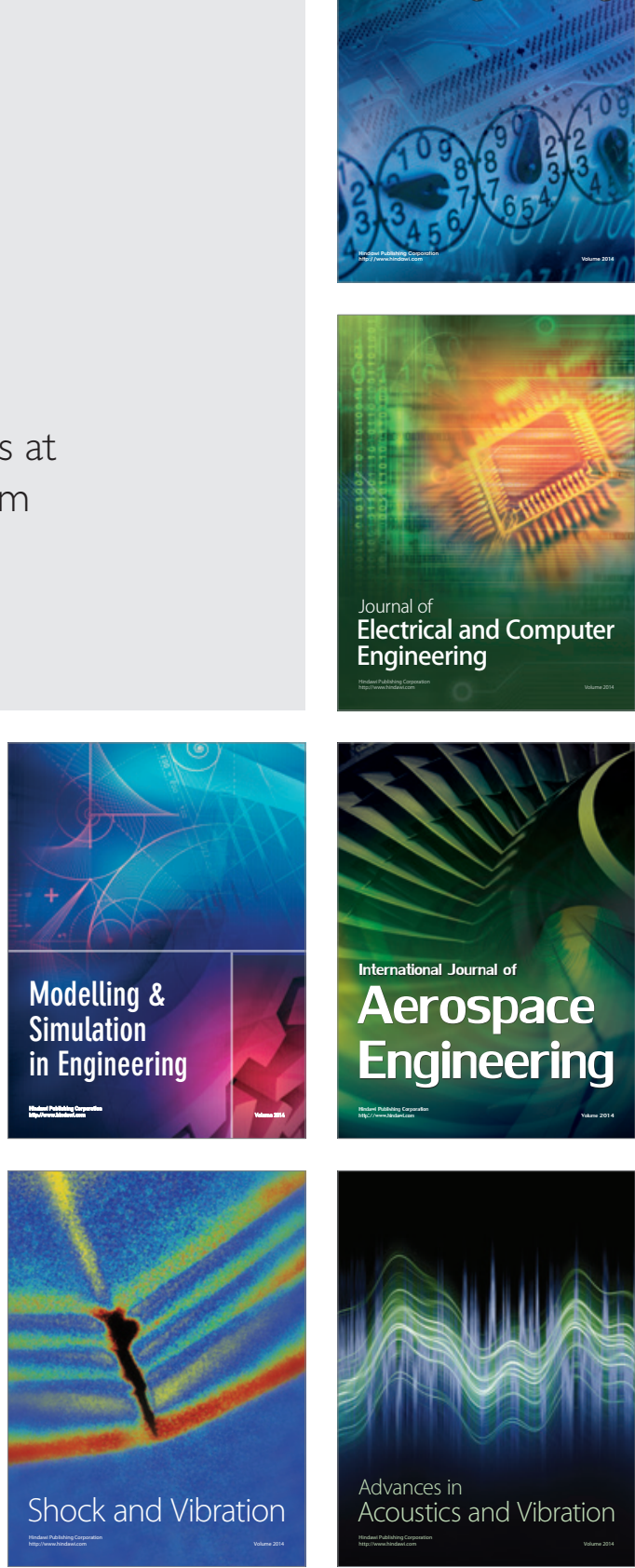